\title{
Carbon nanotubes gathered onto silica particles lose their biomimetic properties with the cytoskeleton becoming biocompatible
}

This article was published in the following Dove Press journal:

International Journal of Nanomedicine

29 August 2017

Number of times this article has been viewed

\author{
Elena González- \\ Domínguez 1 ,* \\ Nerea Iturrioz-Rodríguez ${ }^{2, *}$ \\ Esperanza Padín-González ${ }^{2}$ \\ Juan Villegas ${ }^{2}$ \\ Lorena García-Hevia ${ }^{2}$ \\ Moisés Pérez-Lorenzo \\ Wolfgang J Parak ${ }^{3}$ \\ Miguel A Correa-Duarte ${ }^{1, *}$ \\ Mónica L Fanarraga ${ }^{2, *}$ \\ 'Department of Physical Chemistry, \\ Biomedical Research Center \\ (CINBIO), Southern Galicia \\ Institute of Health Research (IISSG), \\ Biomedical Research Networking \\ Center for Mental Health \\ (CIBERSAM), Universidade de Vigo, \\ Vigo, Spain; ${ }^{2}$ Nanomedicine Group, \\ Universidad de Cantabria-IDIVAL, \\ Santander, Spain; ${ }^{3}$ Department of \\ Physics, Philipps Universität Marburg, \\ Marburg, Germany \\ *These authors contributed equally \\ to this work
}

Correspondence: Mónica L Fanarraga Grupo de Nanomedicina, Universidad de Cantabria-IDIVAL, Herrera Oria s/n, 390II Santander, Spain Email fanarrag@unican.es

\begin{abstract}
Carbon nanotubes (CNTs) are likely to transform the therapeutic and diagnostic fields in biomedicine during the coming years. However, the fragmented vision of their side effects and toxicity in humans has proscribed their use as nanomedicines. Most studies agree that biocompatibility depends on the state of aggregation/dispersion of CNTs under physiological conditions, but conclusions are confusing so far. This study designs an experimental setup to investigate the cytotoxic effect of individualized multiwalled CNTs compared to that of identical nanotubes assembled on submicrometric structures. Our results demonstrate how CNT cytotoxicity is directly dependent on the nanotube dispersion at a given dosage. When CNTs are gathered onto silica templates, they do not interfere with cell proliferation or survival becoming highly compatible. These results support the hypothesis that CNT cytotoxicity is due to the biomimetics of these nanomaterials with the intracellular nanofilaments. These findings provide major clues for the development of innocuous CNT-containing nanodevices and nanomedicines.
\end{abstract}

Keywords: MWCNTs, biomimetics, cytoskeleton, microtubules, apoptosis, migration, proliferation

\section{Introduction}

In the past years, carbon nanotubes (CNTs) have emerged as promising materials in nanomedicine. Their unique structure-dependent properties have shown enormous potential in the design of groundbreaking tools in many different biological fields including biosensing, tissue engineering, intracellular probing, cancer therapy, nanodelivery, and bioimaging. ${ }^{1-5}$ Paradoxically, although no human pathology has been documented because of CNT exposure so far, their asbestos-like morphology and bio-persistence have relapsed their application in nanomedicine.

At the cellular level, there is ample information regarding CNT toxicity. These nanomaterials have been reported to produce a plethora of effects in many cell types including 1) genotoxic responses and DNA breakage, ${ }^{6-11}$ 2) chromosomal malsegregation, ${ }^{11-14} 3$ ) oxidative stress, ${ }^{15-18}$ 4) frustrated phagocytosis, ${ }^{19-23} 5$ ) biomechanical failure, ${ }^{18,24-26}$ and mitochondrial damage. ${ }^{27,28}$ However, these results contrast with many other reports claiming CNTs as biocompatible in different biological systems. ${ }^{29-35}$ This confusing scenario is the result of many different issues.

As reviewed by Marchesan et al, ${ }^{36}$ CNTs represent a highly heterogeneous type of nanomaterials that mainly differ in 1) their sizes - with diameters ranging from $<1 \mathrm{~nm}$ up to $100 \mathrm{~nm}, 2$ ) their lengths - that typically vary from a few hundred nanometers to several microns, 3 ) their purity - containing metal residues that may be present as traces 
or up to $30 \%$ in weight, and 4) their surface properties - that are strongly dependent on the surface functionalization, with all these factors being critical in the cellular response. $22,23,28,31,37$ In addition to the heterogeneity of the startup material, many experimental toxicity assays have been performed following traditional in vitro approaches designed for soluble chemicals. ${ }^{38}$ Unlike these, nanomaterials in general, and CNTs in particular, have a high surface-to-volume ratio, so they often aggregate and sediment. In addition, as the state of aggregation of CNTs in biological aqueous-based environments is critical in mitochondrial proapoptotic protein activation and reactive oxygen species production, ${ }^{28} \mathrm{CNT}$ dispersion adds extra experimental variables to toxicological studies.

To this effect, nanodispersed CNTs have been reported to trigger two major different phenotypes that include chromosomal breakage (clastogenic effects) ${ }^{6-10}$ and cytoskeletal incompetence, ${ }^{12,13,18,24-26}$ and both can be attributed to the biomimetic properties of CNTs with the intracellular nanofilaments, namely DNA and microtubules. Multiwalled carbon nanotubes (MWCNTs) in particular share many properties with microtubules including 1) their tubular shape, 2) lengths, 3) resiliency, 4) and reactive surfaces, ${ }^{39}$ which prompt their interaction in vitro ${ }^{40}$ and in vivo. ${ }^{14}$ The biosynthetic polymers assembled are moderately functional, ${ }^{40}$ but highly stable compared to standard microtubules that typically undergo continuous polymerization/depolymerization cycles in the cell. ${ }^{41}$ The cytoskeletal stability induced by CNT exposure leads to the disassembly of the microtubule nucleation center, known as the centrosome, triggering the disorganization of the typically radial microtubule array. ${ }^{26}$ This effect produces serious biomechanical defects in $\sim 72 \mathrm{~h}$, frustrating cell migration and division and eventually killing the cell. ${ }^{14,18}$ This cytotoxic effect has been reported for different cell types including fibroblasts, ${ }^{42}$ HeLa ${ }^{26}$ microglia, ${ }^{43}$ melanoma, ${ }^{44}$ or glioblastoma ${ }^{26}$ cells, producing interesting in vivo antitumoral effects. ${ }^{44}$

Here we investigate the intrinsic cytotoxicity of CNTs, disconnecting the biomimetic effect from other possible toxicity mechanisms attributed to their composition or physicochemical properties. To perform such studies, we have investigated the cellular response after exposure to well-dispersed CNTs versus controlled assemblies of identical nanotubes. The CNT-bearing structures, key issue in this study, have been obtained by means of the controlled deposition of CNTs onto spherical silica colloids.

\section{Materials and methods}

\section{Chemicals and media}

Rhodamine B isothiocyanate (70\% labeling efficiency), (3-aminopropyl) triethoxysilane (97\%), 4-(dimethylamino)pyridine ( $\geq 99 \%$ ), dicyclohexylcarbodiimide solution ( $\geq 99 \%$ ), triethylamine BioUltra $\geq 99.5 \%$, poly(diallyldimethylammonium chloride) ( $\mathrm{MW}<100,000$ Da), poly-( sodium 4 styrenesulfonate) $(\mathrm{MW}=70,000$ $\mathrm{Da})$, nitric acid $\left(\mathrm{HNO}_{3}, 65 \%\right)$, sodium hydroxide $(\mathrm{NaOH}$, $\geq 97 \%$ ), tetraethyl orthosilicate (TEOS, 98\%), and EtOH were obtained from Sigma-Aldrich Química SL (Madrid, Spain). Multiwalled carbon nanotubes $9.5 \mathrm{~nm}$ in diameter and $1.5 \mu \mathrm{m}$ in length, 95\% C purity, synthesized using Catalytic Chemical Vapor Deposition process, were purchased from Nanocyl as a powder. Ammonium hydroxide solution ( $\mathrm{NH}_{4} \mathrm{OH}, 28 \%-30 \% \mathrm{NH}_{3}$ ), cystamine hydrochloride $97 \%$, N,N-dimethylformamide were obtained from Fluka. Sulfuric acid $\left(\mathrm{H}_{2} \mathrm{SO}_{4}, 96 \%\right)$ was purchased from Panreac and sodium chloride $(\mathrm{NaCl}, \geq 99 \%)$ from Merck.

\section{Synthesis and characterization of the CNT-bearing structures}

Monodisperse silica spheres $(\sim 500 \mathrm{~nm})$ were prepared using a modified Stöber method (Figure S1). Typically, a tetraethyl orthosilicate (TEOS) solution $(1.7 \mathrm{~mL}, 98 \%)$ was added to a solution containing ammonium hydroxide $(1.97 \mathrm{~mL}$, $\left.28 \%-30 \% \mathrm{NH}_{3}\right)$, water $(3.1 \mathrm{~mL})$, and ethanol (18.2 $\left.\mathrm{mL}\right)$, stirring at room temperature for $2 \mathrm{~h}$. The excess of reagents was removed by three centrifugation/redispersion cycles with ethanol (9,000 rpm, $10 \mathrm{~min}$ ). Particles were finally redispersed and stored in water. Silica particles were functionalized with (3-aminopropyl)triethoxysilane (APS) by means of the addition of $0.25 \mathrm{~mL}$ of APS in $5 \mathrm{~mL}$ of an ethanolic dispersion of $\mathrm{SiO}_{2}$ $(8.7 \mathrm{mg} / \mathrm{mL})$. After a 3-h stirring, the excess of reagents was removed by three repeated centrifugation/redispersion cycles with ethanol (7,000 rpm, $20 \mathrm{~min})$. Then, the APS-functionalized $\mathrm{SiO}_{2}$ particles were diluted in $10 \mathrm{~mL}$ of EtOH and added to $10 \mathrm{~mL}$ of an ethanolic solution of rhodamine $\mathrm{B}$ isothiocyanate (RBITC) $(0.32 \mathrm{mg} / \mathrm{mL})$. After a 3-h stirring, the excess of dye was removed by three repeated centrifugation/redispersion cycles (7,000 rpm, $20 \mathrm{~min}$ ), affording an aqueous solution of fluorescent-labeled silica particles $\left(f-\mathrm{SiO}_{2}\right)$. CNT functionalization was performed using MWCNTs pretreated with acetone and ethanol to remove organic materials, frozen with $\mathrm{N}_{2}$ and lyophilized. Then, $100 \mathrm{mg}$ of the purified MWCNTs was oxidized by sonication in $100 \mathrm{~mL}$ of a mixture of $\mathrm{H}_{2} \mathrm{SO}_{4} /$ $\mathrm{HNO}_{3}(3: 1)$ for $15 \mathrm{~min}$ with an ultrasonic probe $(20 \mathrm{~W})$ and $4 \mathrm{~h}$ in an ultrasonic bath. Then, the sample was washed with an $\mathrm{NaOH}$ aqueous solution by three centrifugation/redispersion cycles $(13,000 \mathrm{rpm}, 4 \mathrm{~h})$. Upon stabilization of $\mathrm{pH}$ at 10 , the sample was sonicated with the tip sonicator for $2 \mathrm{~h}$. Then, the MWCNTs were washed with water by three centrifugation/ redispersion cycles $(13,000 \mathrm{rpm}, 8 \mathrm{~h})$. Finally, a stable dispersion 
(1.54 mg/mL) of oxidized MWCNTs (ox-MWCNTs) exhibiting a negative surface charge was obtained. Then, the oxMWCNTs were assembled onto the labeled silica spheres. With this aim, the positively charged $f-\mathrm{SiO}_{2}$ nanoparticles (zeta potential $=+40 \mathrm{mV}$ ) were functionalized by successive depositions of oppositely charged polyelectrolytes (poly-(sodium 4 styrenesulfonate)/poly(diallyldimethylammonium chloride)) giving rise to a positively charged surface. The deposition of the different polymers was performed following the same protocol. $f-\mathrm{SiO}_{2}$ spheres were added to a polymer solution $(1 \mathrm{mg} / \mathrm{mL}, 0.5 \mathrm{M} \mathrm{NaCl})$ under weak sonication for $1 \mathrm{~h}$. The excess of polymer was removed by three centrifugation/redispersion cycles ( $20 \mathrm{~min}, 8,000 \mathrm{rpm}$ ). Then, $2 \mathrm{~mL}$ of an aqueous solution of $\mathrm{NaCl}(0.5 \mathrm{M})$ and $3 \mathrm{~mL}$ of an aqueous dispersion of ox-MWCNTs $(1.54 \mathrm{mg} / \mathrm{mL})$ were added to $100 \mathrm{~mL}$ of the positively charged $f-\mathrm{SiO}_{2}$ nanoparticles $(0.87 \mathrm{mg} / \mathrm{mL})$ and mixed under stirring for $15 \mathrm{~h}$. Finally, the excess of MWCNTs was removed by three repeated centrifugation/redispersion cycles (7,000 rpm, $20 \mathrm{~min})$, and the MWCNT-coated $f-\mathrm{SiO}_{2}$ spheres were dispersed in water $(3.8 \mathrm{mg} / \mathrm{mL}$ with an $f-\mathrm{SiO}_{2}$ :MWCNT wt. 22:1). The concentration of MWCNTs deposited onto the $f-\mathrm{SiO}_{2}$ nanoparticles was calculated by measuring the difference between the initial amount of nanotubes and that obtained in the supernatant of the centrifugationwashing step. The characterization of these composites was performed using transmission electron microscopy (TEM).

\section{Cell culture, labeling, and microscopy imaging}

HeLa cells (from the European Molecular Biology Laboratory Cell Bank) were cultured under standard conditions in Dulbecco's Modified Eagle's Medium containing 10\% serum and containing antibiotics (from Gibco, Thermo Fisher Scientific, Waltham, MA, USA). Cells were incubated with $2-4 \mu \mathrm{g} / \mathrm{mL}$ of particles (unless otherwise indicated in the text) resuspended and functionalized by mild sonication in standard tissue culture medium containing serum. Cells were fixed in 4\% paraformaldehyde. Microtubules were immunolabeled with the anti- $\alpha$-tubulin (B512) (Sigma-Aldrich Química SL, Madrid, Spain) antibody that was recognized by a secondary goat anti-mouse immunoglobulin $\mathrm{G}(\mathrm{IgG})$ conjugated Alexa Fluor 488 (Molecular Probes, Thermo Fisher Scientific). Phalloidin-tetramethylrhodamine B isothiocyanate and Hoechst dye (Bisbenzimide) (both from Sigma-Aldrich Química SL) were used to stain actin and DNA, respectively. Confocal microscopy images were obtained with a Nikon A1R confocal microscope and were processed with the NIS-Elements Advanced Research software. High-resolution confocal imaging was performed using a Plan Apochromatic
$100 \times$ oil numerical aperture 1.45 objective. All confocal cell images are pseudocolored. Live-cell phase-contrast imaging was performed on a live-cell Nikon-Ti live-cell station. TEM was also used to localize intracellular the CNT-bearing particles (CNPs) in pelleted HeLa cells fixed with $1 \%$ glutaraldehyde in $0.12 \mathrm{M}$ phosphate buffer, washed in $0.12 \mathrm{M}$ phosphate buffer, postfixed in $1 \%$ buffered osmium tetroxide, dehydrated, embedded in Araldite, and stained with lead citrate-uranyl acetate. Araldite sections (ca. $70 \mathrm{~nm}$ ) were observed using a JEOL JEM 1011 microscope.

\section{Particle quantification, live-cell assessment, and statistical analysis}

Particle quantification was performed on random $20 \times$ magnification fluorescent images of the HeLa cell cultures. The Image-J software was used for random automatic quantification of extracellular versus intracellular particles. The total number of intracellular particles after overnight incubation was considered a $100 \%$. The Student's $t$-test was used to perform the statistical analysis and to evaluate significance. Cell death was identified and quantified using a standard Trypan blue exclusion assay. Cell proliferation blockage was performed using flow cytometry in a total of ca. 10,000 fixed and stained HeLa cells (per condition) in a Becton Dickinson FACS CantoII equipment. Data were analyzed using the FACS Diva software (Becton Dickinson, NJ, USA).

\section{Microtubule depolymerization- repolymerization experiments}

This assay was performed as previously described ${ }^{14}$ following classical protocols. ${ }^{45}$ The microtubule tubulin polymer disassembles under low-temperature conditions $\left(4^{\circ} \mathrm{C}, 30 \mathrm{~min}\right)$, repolymerizing in minutes under permissive temperatures $\left(37^{\circ} \mathrm{C}\right)$. Microtubule depolymerization was performed with culture medium at $4^{\circ} \mathrm{C}$, containing $2 \mu \mathrm{M}$ nocodazole for $30 \mathrm{~min}$. Microtubule regrowth was performed placing coverslips into fresh media at $37^{\circ} \mathrm{C}$ and cells were snap fixed in $1 \%$ glutaraldehyde at the indicated times.

\section{Results \\ CNP design}

The synthesis of uniform CNPs was carried out following the approach depicted in Figure 1. In a first step (Figure 1AI) $\mathrm{SiO}_{2}$ particles of ca. $500 \mathrm{~nm}$ were functionalized with RBITC, a fluorescence label that allows confocal microscopy intracellular particle tracking. The electrostatic deposition of negatively charged oxidized nanotubes onto fluorescence silica colloids $\left(f-\mathrm{SiO}_{2}\right)$ was performed as previously described 
A
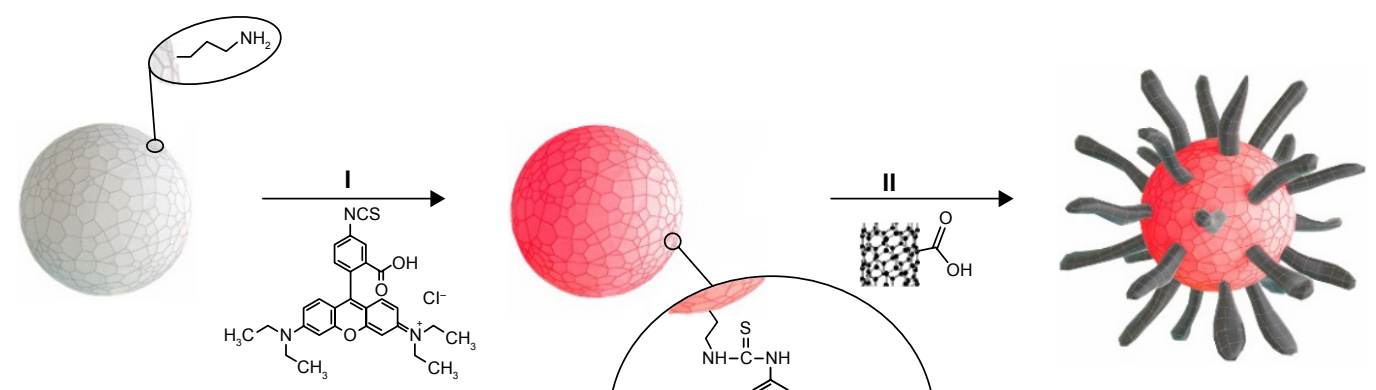

B

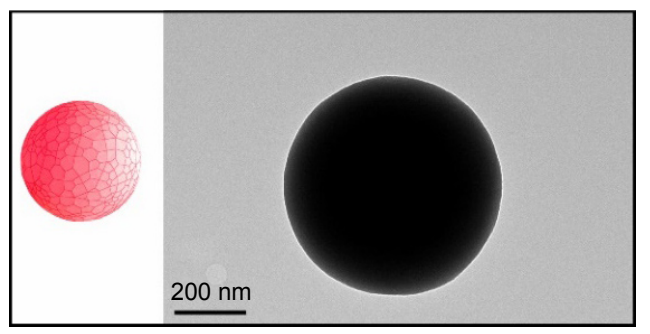

D RBITC-nude particles

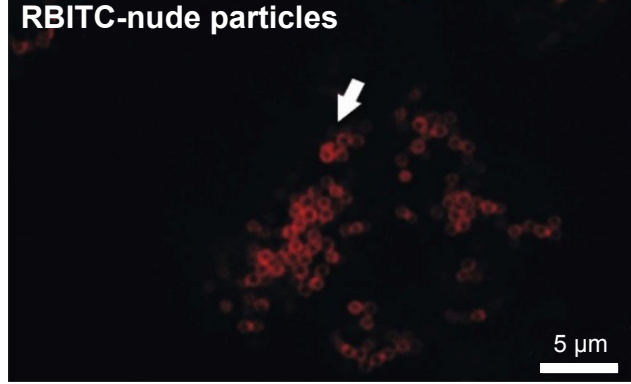

C

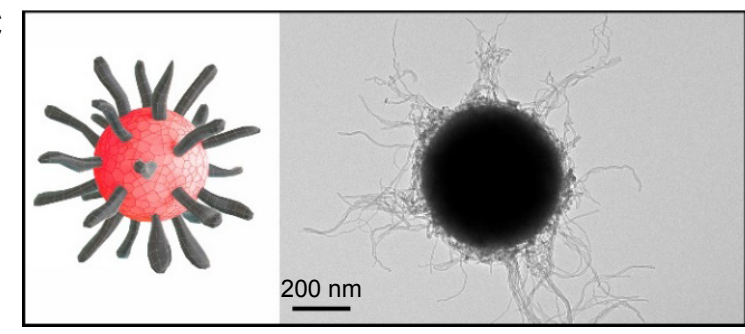

E
RBITC-CNPs

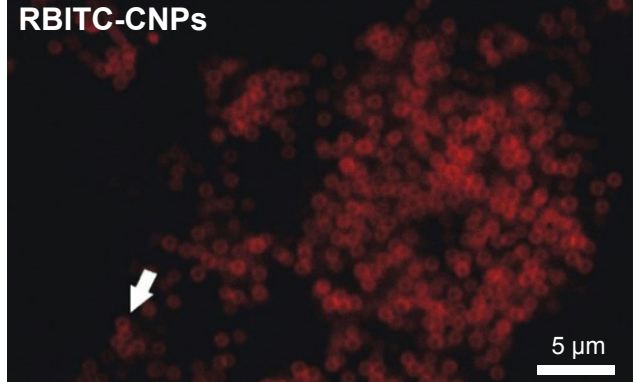

Figure I Diagram of the fabrication process of the fluorescent CNPs.

Notes: (A) Sequential synthetic steps: (I) fluorescent labeling of the $\mathrm{SiO}_{2}$ particles ( $f-\mathrm{SiO}_{2}$ ), and (II) deposition of CNTs onto the $f$-SiO ${ }_{2}$ spheres (CNP). TEM images of (B) $\mathrm{f}_{-} \mathrm{SiO}_{2}$ particles and (C) CNPs. Confocal microscopy image of the RBITC fluorescence on $\mathrm{f}-\mathrm{SiO}_{2}$ particles (D) and (E) CNPs in buffered culture medium. Arrows point to individual particles in single Z-plane confocal images.

Abbreviations: CNP, CNT-bearing particle; CNTs, carbon nanotubes; $f$-SiO ${ }_{2}$, fluorescent-labeled silica particles; RBITC, rhodamine B isothiocyanate; TEM, transmission electron microscopy.

(Figure 1AII, see "Materials and methods"). ${ }^{46-48}$ Figure 1B shows representative TEM images of the $f-\mathrm{SiO}_{2}$ particles used as uncoated controls, while Figure $1 \mathrm{C}$ shows the CNPs synthesized herein, as uniform and controlled assemblies of nanotubes. All these structures were finally coated with adsorbed serum proteins so they could be recognized by different cell-surface receptors on the cell membrane of HeLa cells, triggering receptor-mediated endocytosis as described for MWCNTs. ${ }^{49,50}$

\section{CNP engulfment by HeLa cells}

Particle engulfment was investigated using time-lapse video microscopy (Video S1). Endocytosis started a few minutes after the CNPs landed on the cell surface with ca. 50\% of the particles being intracellular $2 \mathrm{~h}$ after the addition of the CNPs in the culture medium (Figure 2). The intracellular distribution of the CNPs was determined using confocal microscopy imaging at different time points. CNP accumulation was significant in the vicinities of the nucleus, at the pericentrosomal region, 72-96 h after particle exposure. On the contrary to MWCNTs exposure, tubulin immunostaining revealed an intact microtubule cytoskeleton, irradiating from a well-organized centrosome (Figure 2B, arrows).

Further characterization of the CNP-cellular contact and the study of the intracellular fate of these particles was performed by TEM analysis. Figure 3 shows different steps in particle engulfment. First, the CNTs on the surface of the CNPs contact the HeLa surface, being eventually trapped 
A
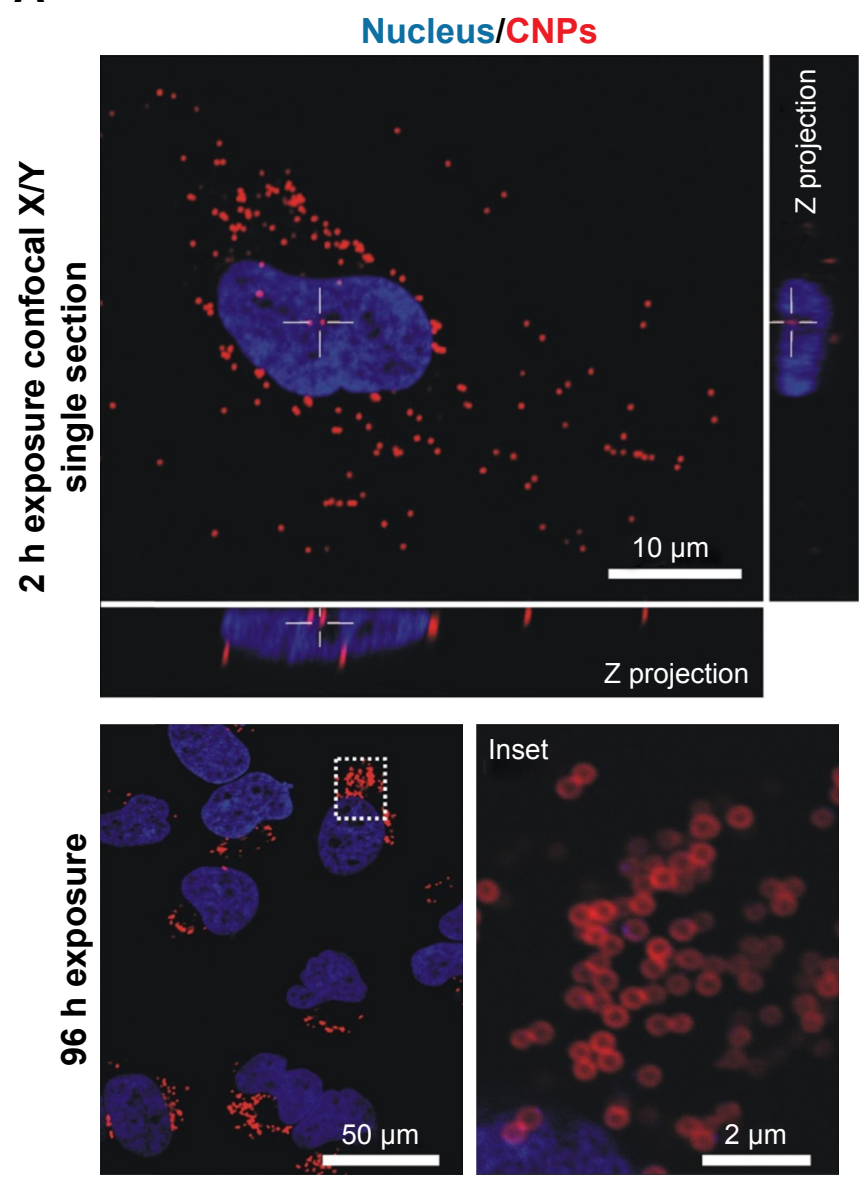

B

B Microtubules/nucleus/

CNPs
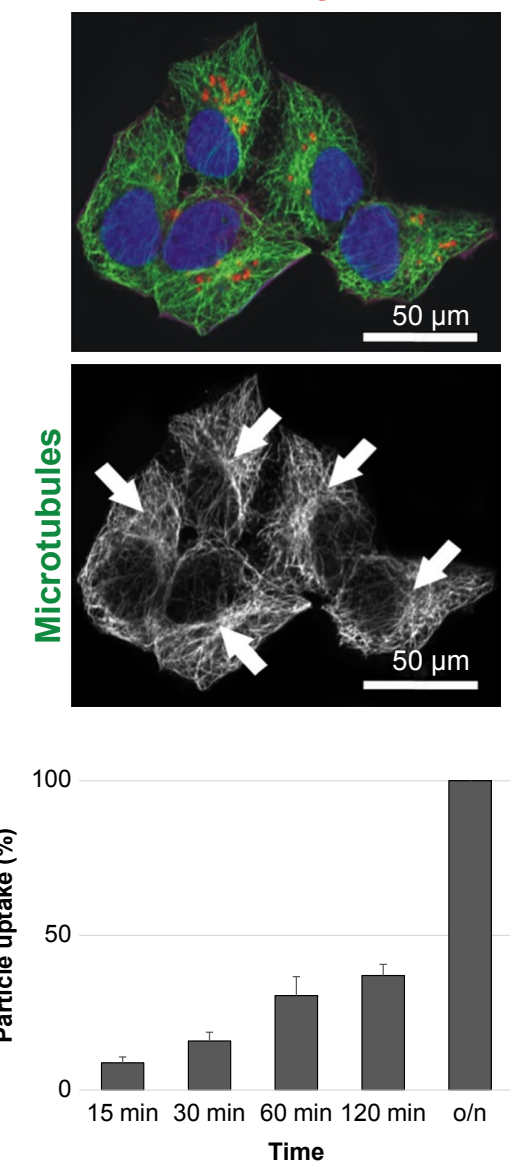

Figure 2 CNP cellular uptake and intracellular distribution.

Notes: (A) Confocal microscopy image of HeLa cells containing intracellular CNPs at 2 and $96 \mathrm{~h}$. The white cross (also visible in the lateral projections) indicates the position of a cytoplasmic particle (red channel) $2 \mathrm{~h}$ after exposure. CNPs accumulate at the centrosomal region of the cells $96 \mathrm{~h}$ after initial contact (inset). (B) Confocal microscopy projection image of HeLa cells containing fluorescent CNPs displaying no abnormalities in the microtubule cytoskeleton. These tubulin nanofilaments irradiate from wellorganized centrosomes (arrows). Cell nuclei (blue channel) of cells exposed to CNPs present a healthy appearance.

Abbreviations: CNP, CNT-bearing particle; CNTs, carbon nanotubes; o/n, overnight.

inside endocytic membranes. The CNT-based coating surrounding the silica templates can be clearly visualized inside the endocytic vesicles (Figure 3, arrows). HeLa cells exposed to CNPs during $72 \mathrm{~h}$ presented many particles localized inside the cytosol with their CNT coverture fully integrated in the surrounding cytoplasm, and no visible surrounding membranes. All these experiments support the idea that the entry of CNPs inside HeLa cells is similar to that described for dispersed CNTs. ${ }^{49,50}$

\section{CNTs attached to templates are not cytotoxic}

Well-dispersed CNTs, and more particularly MWCNTs, trigger significant microtubule cytoskeleton disrupting effects that lead to antiproliferative effects and cell death in different cell types. Here we compare the effects of CNTs delivered to the cells in two different formats. On one hand, we exposed HeLa cells to fully dispersed one-dimensional (1D) functionalized CNTs as in previous studies. ${ }^{14}$ On the other hand, cells were exposed to functionalized CNPs containing comparable amounts of CNTs attached to their surfaces. Cells were grown in the presence of these nanomaterials for $72 \mathrm{~h}$ before morphological and cell viability evaluation.

As previously reported, ${ }^{14,26,51}$ cells exposed to dispersed CNTs displayed a disorganized microtubule cytoskeleton with no detectable centrosomes and a reorganized actin cortex (Figure 4). Cell death quantification using the Trypan blue exclusion test revealed that exposure to dispersed CNTs triggered a reduction of ca. $6.5 \%$ cell viability during the first 48-72 h, thus coinciding with published observations. ${ }^{14,52}$

On the contrary, HeLa cells exposed to CNPs containing identical amounts of CNTs attached to their surfaces displayed 

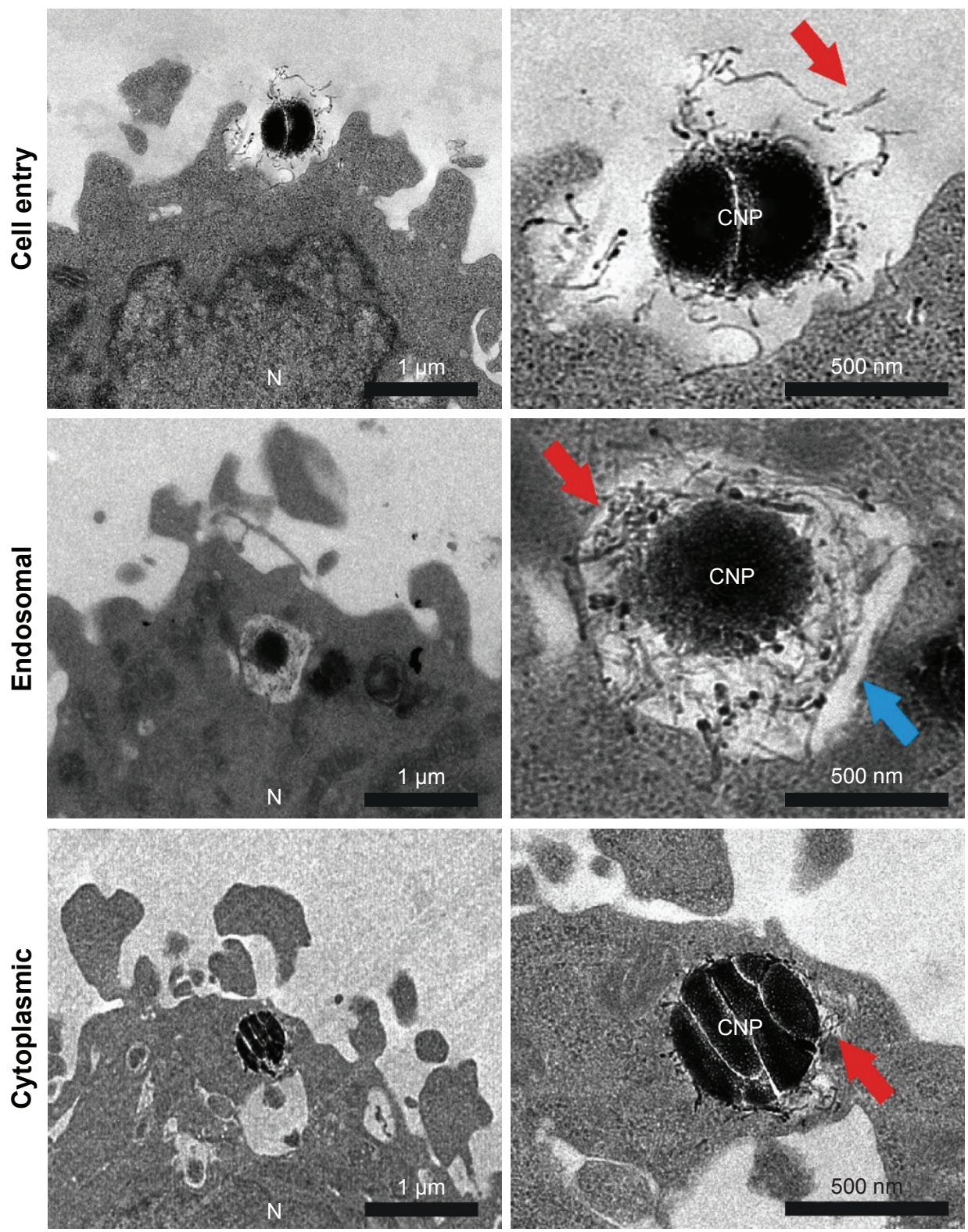

Figure 3 TEM imaging of resin section of HeLa cells exposed to CNPs.

Notes: CNP initial contact is CNT-mediated. The endocytic membranes are observed in some particles, presumably after endocytosis. Some particles also appear devoid of membranes, inside the cytoplasm. Red and blue arrows point at the CNTs attached on the surface of the CNPs and endosomal membrane, respectively. The nucleus (N) is also labeled.

Abbreviations: CNP, CNT-bearing particle; CNT, carbon nanotube; TEM, transmission electron microscopy.

a well-organized cytoskeleton, with a visible centrosome and nonreactive actin microfilaments on the cellular cortex despite the large number of CNPs per cell ( $>100$ particles/ cell) (Figure 4A, arrows). Interestingly, cells exposed to CNPs displayed identical survival rates to cells exposed to $f-\mathrm{SiO}_{2}$ particles or untreated controls (Figure 4B).

To investigate if intracellular CNPs interfered in cell division, we quantified cells at the different proliferation cycle stages using flow cytometry in a total population of $\sim 10,000$ cells per condition. As expected, cells treated with dispersed CNTs displayed a severe dosage-dependent proliferative blockage in G2 (Figure 5A) just as previously reported. Conversely, cells exposed to CNPs displayed no detectable cell-cycle defects, dividing normally. Confocal microscopy morphological assessment of the proliferating cells in these cultures revealed normal bipolar spindle assemblies in cells exposed to CNPs that contrasted to the large collection of spindle abnormalities observed in cells exposed to dispersed CNTs. These aberrations included apolar, tripolar, or multipolar spindles, 
A Nucleus/actin/
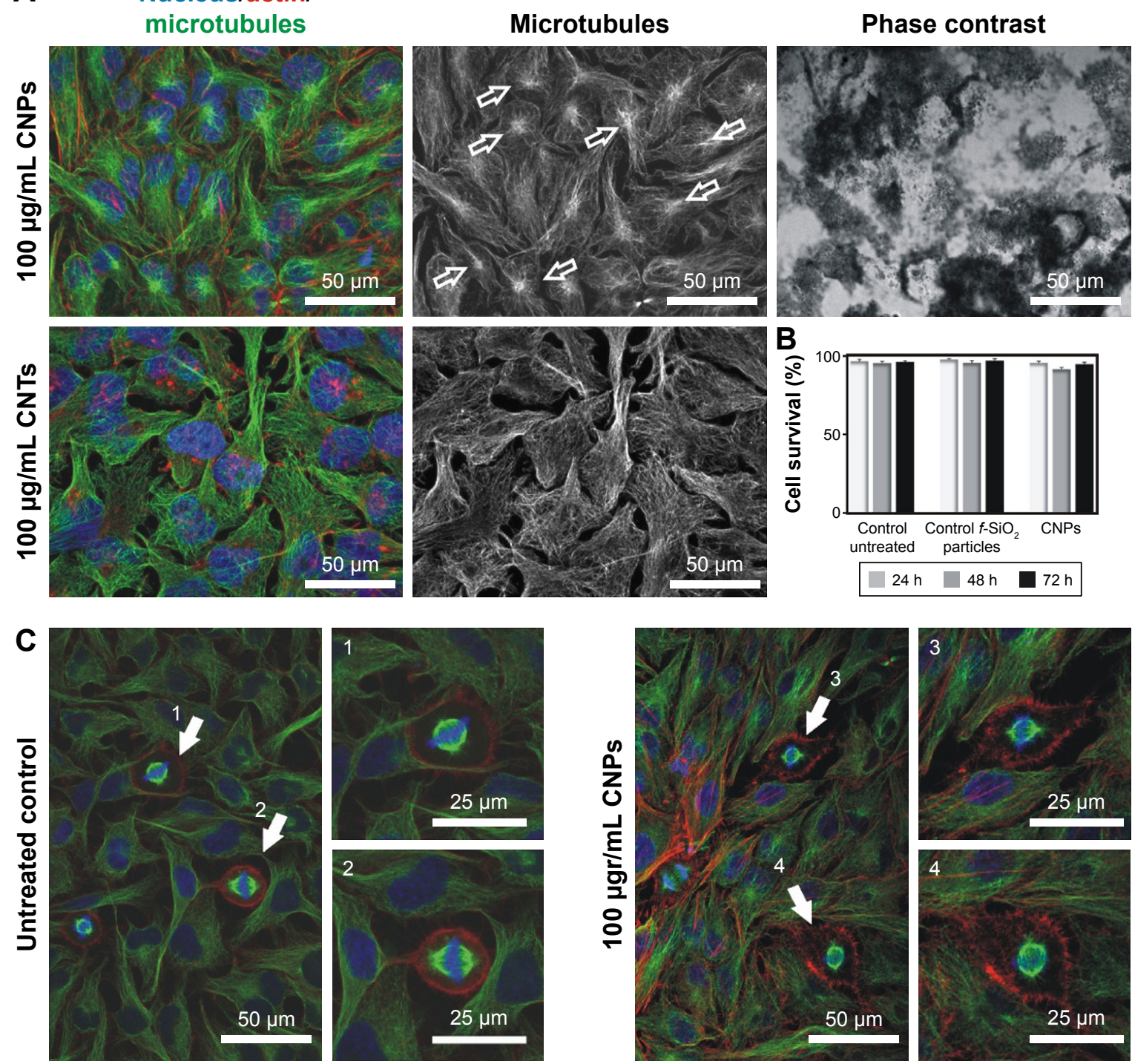

Figure 4 CNPs are highly biocompatible.

Notes: (A) Confocal microscopy images of the intracellular nanofilaments in interphase cells treated with CNPs (top) or CNTs (bottom) for 72 h. CNP-treated cells display a well-organized radial cytoskeleton with visible centrosomes (green channel, empty arrows). On the contrary, cells exposed to CNTs show a typically disorganized microtubule cytoskeleton displaying no visible centrosomes and a reactive actin cortex (red channel). (B) CNP-treated cells display a survival rate comparable to controls. (C) Control and HeLa cell cultures exposed to CNPs for $72 \mathrm{~h}$. CNP-treated cells display well-assembled spindles $(3,4)$ compared to untreated control cells $(\mathrm{I}, 2)$. Dying cells were not detected.

Abbreviations: CNPs, CNT-bearing particles; CNTs, carbon nanotubes.

accompanied by many apoptotic figures (Figure 5B). In summary, we observed no obvious cytotoxic or proliferative effects in cells treated with CNTs attached to silica templates. These results stress the importance of the dispersion of CNTs in cytotoxicity.

\section{CNTs gathered on CNPs do not nucleate tubulin or actin nanofilaments}

Tubulin and, to a lesser extent, actin have shown biomimetic properties with MWCNTs. To explore if these features are maintained when CNTs are gathered onto CNPs, we investigated tubulin and actin polymer nucleation on these templates following previous protocols ${ }^{14}$ that reproduced classical microtubule depolymerization-repolymerization experiments ${ }^{45}$ on live cells containing 5-15 particles/cell ("Materials and methods"). This procedure allowed to investigate if grouped CNTs could nucleate tubulin polymers ectopically, behaving as "artificial" centrosomes.

Figure 6 shows high-resolution confocal microscopy images of cells where microtubule ectopic nucleation sites coinciding with the CNPs were not detected after depolymerization-repolymerization. Actin recruitment 
A
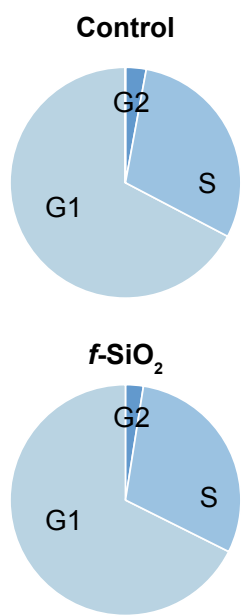

CNPs

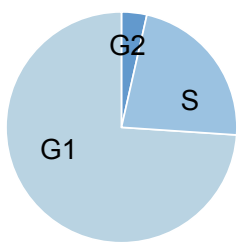

Cell cycle

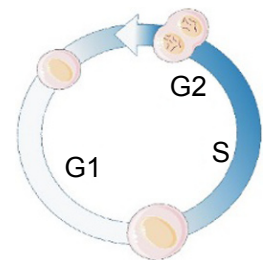

CNTs $50 \mu \mathrm{gr} / \mathrm{mL}$

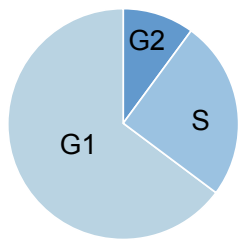

CNTs $100 \mu \mathrm{gr} / \mathrm{mL}$

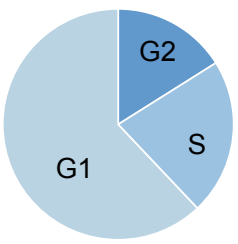

B Chromosomes/microtubules
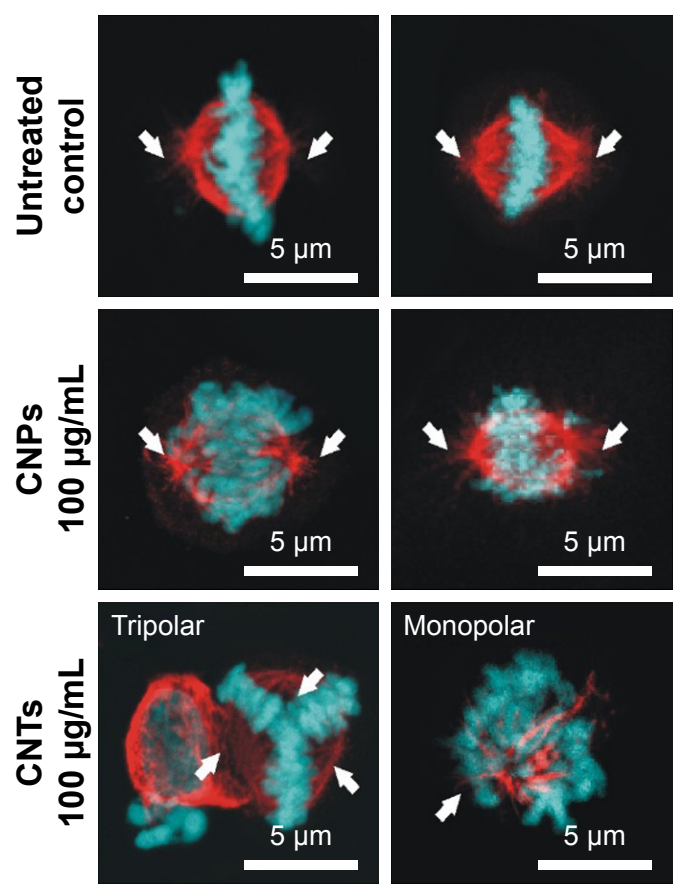

Figure 5 (A) CNPs do not interfere with cell proliferation.

Notes: Quantification of cells at the different stages of the cell proliferation cycle (GI, S, G2) using flow cytometry. CNPs display a similar cell distribution to controls (untreated and $\mathrm{f}_{-} \mathrm{SiO}_{2}$-treated cells). Conversely, CNT-treated cells show an obvious dose-dependent cell proliferation blockage in $\mathrm{G} 2$. (B) Confocal microscopy projection images of mitotic spindles in untreated controls and cells treated with $100 \mu \mathrm{g} / \mathrm{mL}$ attached to CNPs or dispersed (bottom). Aberrations in the organization of the spindle microtubules (red channel) are observed only in CNT-treated cells. White arrows show the centrosomal location. Abbreviations: CNPs, CNT-bearing particles; CNT, carbon nanotube; $f-\mathrm{SiO}_{2}$, fluorescent-labeled silica particles.

A

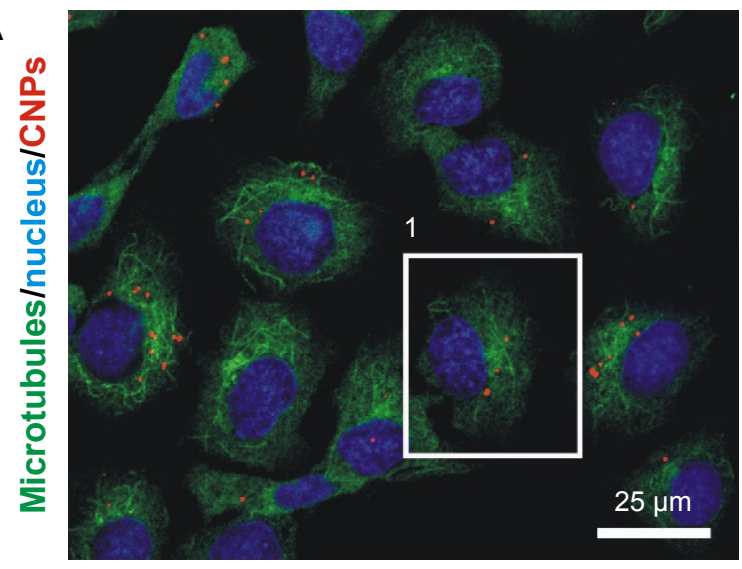

B

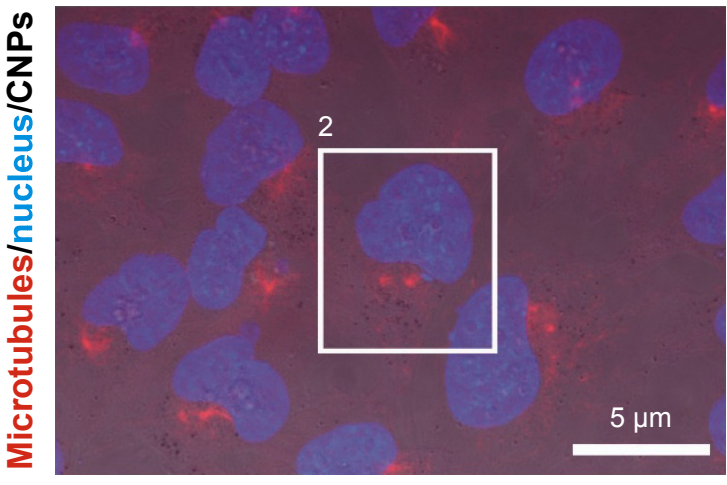

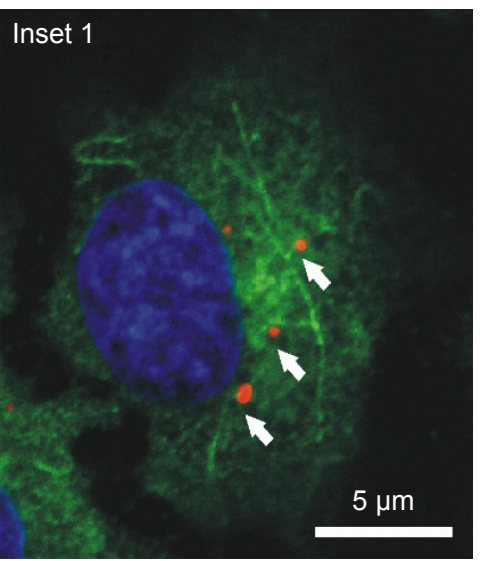

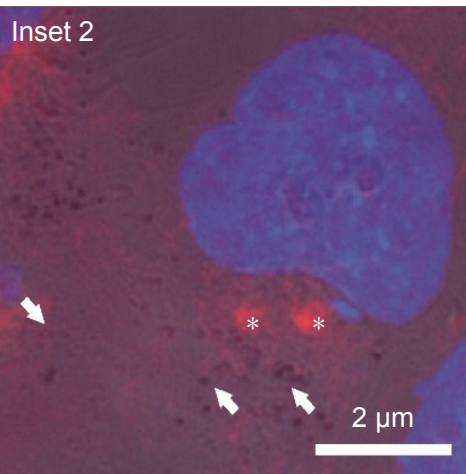

Figure 6 (Continued) 

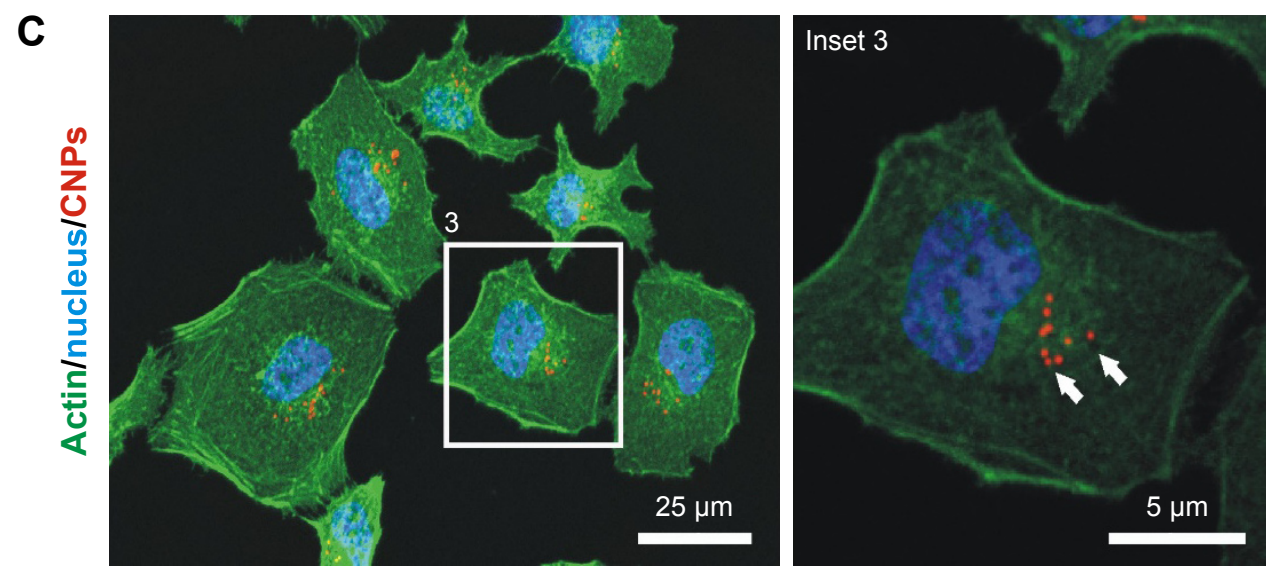

Figure 6 Depolymerization/repolymerization experiment performed in live HeLa cells containing CNPs.

Notes: (A) Confocal microscopy image of HeLa cells containing CNPs (red channel, arrows). Repolymerizing microtubules (green channel) do not nucleate at the particles. (B) Fluorescence + phase contrast microscopy on HeLa cells treated with unlabeled CNPs (arrows). The CNT coating of the particle allows particle identification in the phase contrast image. No tubulin nucleation (red channel) is observed in the surroundings of the CNPs. Asterisks indicate the location of the centrosomes. (C) Actin nucleation (green channel) is not observed in the surroundings of the CNPs (arrows)

Abbreviations: CNPs, CNT-bearing particles; CNT, carbon nanotube.

on the CNPs was not detected either. In conclusion, these polymerization patterns suggest that neither tubulin nor actin interacted with CNTs gathered on CNPs, and validate the hypothesis of the biomimetic interaction of 1D CNTs with the intracellular cytoskeletal filaments.

\section{Conclusion}

These experiments demonstrate how the presence of intracellular CNTs is not sufficient to trigger cytotoxicity, and how this is determined by the dispersion of the CNTs. Our experiments support the idea that individualized CNTs can freely interact with the cellular filaments, triggering lethal biomimetic cytotoxic or genotoxic effects, while identical CNTs assembled onto templates cannot interfere with the function of intracellular nanofilaments, and thus, result innocuous to the same cells at comparable dosages. The simplest explanation is that dispersed nanotubes behave as nanomaterials, while CNPs behave like submicrometric materials. This fact has critical implications in biology because nanomaterials, and in particular CNTs, display highly reactive surfaces, as well as morphological resemblance to the cytoskeletal elements that favor their biomimetic interaction triggering a biomechanical impedance that leads to cell death. When CNTs are attached to templates, these nanofilaments do not interact with the cellular cytoskeleton behaving more like particulate materials, and thus becoming more biocompatible. These urge the revision of many of the nanotoxicological tests, often designed for standard chemicals now applied to nanomaterials. Here we demonstrate how the classical Paracelsus dogma "the dose makes the poison" is not applicable for CNTs.
Understanding the actual significance of the toxicity of CNTs provides new cues in the development of radically new delivery systems opening many new expectations and uses of CNTs in nanomedicine.

\section{Acknowledgments}

The authors are grateful to Drs Sumaira Ashraf and Iñigo Casafont for their technical assistance with microscopy analysis, and the Nikon A1R Laser Microscopy Unit of the IDIVAL Institute for the microscopy. This work was supported by the Spanish MINECO Project (references PI13/01074, PI16/00496 and CTM2014-58481-R, IDIVAL INNVAL15/15), Xunta de Galicia (Centro Singular de Investigación de Galicia-Accreditation 2016-2019 and EM2014/035), European Regional Development Fund ERDF and Fundación Tatiana Pérez de Guzmán El Bueno.

\section{Disclosure}

The authors report no conflicts of interest in this work.

\section{References}

1. Mehra NK, Mishra V, Jain NK. A Review of ligand tethered surface engineered carbon nanotubes. Biomaterials. 2014;35(4):1267-1283.

2. De Volder MF, Tawfick SH, Baughman RH, Hart AJ. Carbon nanotubes: present and future commercial applications. Science. 2013;339(6119): 535-539.

3. Hernández-Rivera M, Zaibaq NG, Wilson LJ. Toward carbon nanotube-based imaging agents for the clinic. Biomaterials. 2016;101: 229-240.

4. Sajid MI, Jamshaid U, Jamshaid T, Zafar N, Fessi H, Elaissari A. Carbon nanotubes from synthesis to in vivo biomedical applications. Int J Pharm. 2016;501(1-2):278-299.

5. Correa-Duarte MA, Wagner N, Rojas-Chapana J, et al. Fabrication and biocompatibility of carbon nanotube-based 3D networks as scaffolds for cell seeding and growth. Nano Lett. 2004;4(11):2233-2236. 
6. Di Giorgio ML, Di Bucchianico S, Ragnelli AM, Aimola P, Santucci S, Poma A. Effects of single and multi walled carbon nanotubes on macrophages: cyto and genotoxicity and electron microscopy. Mutat Res. 2011;722(1):20-31.

7. Ghosh M, Chakraborty A, Bandyopadhyay M, Mukherjee A. Multi-walled carbon nanotubes (MWCNT): induction of DNA damage in plant and mammalian cells. J Hazard Mater. 2011;197: 327-336.

8. Guo Y-Y, Zhang J, Zheng Y-F, Yang J, Zhu X-Q. Cytotoxic and genotoxic effects of multi-wall carbon nanotubes on human umbilical vein endothelial cells in vitro. Mutat Res. 2011;721(2):184-191.

9. Cveticanin J, Joksic G, Leskovac A, Petrovic S, Sobot AV, Neskovic O. Using carbon nanotubes to induce micronuclei and double strand breaks of the DNA in human cells. Nanotechnology. 2010;21(1):15102.

10. Siegrist KJ, Reynolds SH, Kashon ML, et al. Genotoxicity of multiwalled carbon nanotubes at occupationally relevant doses. Part Fiber Toxicol. 2014;11:6.

11. Muller J, Decordier I, Hoet PH, et al. Clastogenic and aneugenic effects of multi-wall carbon nanotubes in epithelial cells. Carcinogenesis. 2008;29(2):427-433.

12. Sargent LM, Hubbs AF, Young SH, et al. Single-walled carbon nanotube-induced mitotic disruption. Mutat Res. 2012;745(1-2): 28-37.

13. Gonzalez L, Decordier I, Kirsch-Volders M. Induction of chromosome malsegregation by nanomaterials. Biochem Soc Trans. 2010;38(6): 1691-1697.

14. Rodríguez-Fernández L, Valiente R, González J, Villegas JC, Fanarraga ML. Multiwalled carbon nanotubes display microtubule biomimetic properties in vivo, enhancing microtubule assembly and stabilization. ACS Nano. 2012;6(8):6614-6625.

15. Srivastava RK, Pant AB, Kashyap MP, et al. Multi-walled carbon nanotubes induce oxidative stress and apoptosis in human lung cancer cell line-A549. Nanotoxicology. 2011;5(2):195-207.

16. Reddy AR, Reddy YN, Krishna DR, Himabindu V. Multi wall carbon nanotubes induce oxidative stress and cytotoxicity in human embryonic kidney (HEK293) cells. Toxicology. 2010;272(1-3):11-16.

17. Migliore L, Saracino D, Bonelli A, et al. Carbon nanotubes induce oxidative DNA damage in RAW 264.7 Cells. Environ Mol Mutagen. 2010; 51(4):294-303.

18. Dong C, Eldawud R, Sargent LM, et al. Carbon nanotube uptake changes the biomechanical properties of human lung epithelial cells in a time-dependent manner. J Mater Chem B Mater Biol Med. 2015;3: 3983-3992.

19. Lacerda L, Russier J, Pastorin G, et al. Translocation mechanisms of chemically functionalised carbon nanotubes across plasma membranes. Biomaterials. 2012;33(11):3334-3343.

20. Maruyama K, Haniu H, Saito N, et al. Endocytosis of multiwalled carbon nanotubes in bronchial epithelial and mesothelial cells. Biomed Res Int. 2015;2015:793186.

21. Poland CA, Duffin R, Kinloch I, et al. Carbon nanotubes introduced into the abdominal cavity of mice show asbestos-like pathogenicity in a pilot study. Nat Nanotechnol. 2008;3(7):423-428.

22. Ali-Boucetta H, Nunes A, Sainz R, et al. Asbestos-like pathogenicity of long carbon nanotubes alleviated by chemical functionalization. Angew Chem Int Ed Engl. 2013;52(8):2274-2278.

23. Nagai H, Okazaki Y, Chew SH, et al. Diameter and rigidity of multiwalled carbon nanotubes are critical factors in mesothelial injury and carcinogenesis. Proc Natl Acad Sci USA. 2011;108(49): E1330-E1338.

24. Holt BD, Shams H, Horst TA, et al. Altered cell mechanics from the inside: dispersed single wall carbon nanotubes integrate with and restructure actin. J Funct Biomater. 2012;3(2):398-417.

25. Wang J, Sun P, Bao Y, Liu J, An L. Cytotoxicity of single-walled carbon nanotubes on PC12 cells. Toxicol In Vitro. 2011;25(1):242-250.

26. García-Hevia L, Valiente R, Fernández-Luna JL, et al. Inhibition of cancer cell migration by multiwalled carbon nanotubes. Adv Healthc Mater. 2015;4(11):1640-1644.
27. Ma X, Zhang LH, Wang LR, et al. Single-walled carbon nanotubes alter cytochrome c electron transfer and modulate mitochondrial function. ACS Nano. 2012;6(12):10486-10496.

28. Wang LR, Xue X, Hu XM, et al. Structure-dependent mitochondrial dysfunction and hypoxia induced with single-walled carbon nanotubes. Small. 2014;10(14):2859-2869.

29. Garibaldi S, Brunelli C, Bavastrello V, Ghigliotti G, Nicolini C. Carbon nanotube biocompatibility with cardiac muscle cells. Nanotechnology. 2006;17(2):391-397.

30. Mooney E, Dockery P, Greiser U, Murphy M, Barron V. Carbon nanotubes and mesenchymal stem cells: biocompatibility, proliferation and differentiation. Nano Lett. 2008;8(8):2137-2143.

31. Vittorio O, Raffa V, Cuschieri A. Influence of purity and surface oxidation on cytotoxicity of multiwalled carbon nanotubes with human neuroblastoma cells. Nanomedicine. 2009;5(4):424-431.

32. Ju L, Zhang G, Zhang X, et al. Proteomic analysis of cellular response induced by multi-walled carbon nanotubes exposure in A549 cells. PLoS One. 2014;9(1):e84974.

33. Yehia HN, Draper RK, Mikoryak C, et al. Single-walled carbon nanotube interactions with HeLa cells. J Nanobiotechnology. 2007;5:8.

34. Lobo AO, Antunes EF, Machado AHA, Pacheco-Soares C, TravaAiroldi VJ, Corat EJ. Cell viability and adhesion on as grown multi-wall carbon nanotube films. Mater Sci Eng C. 2008;28(2):264-269.

35. Pacurari M, Qian Y, Fu W, et al. Cell permeability, migration, and reactive oxygen species induced by multi-walled carbon nanotubes in human microvascular endothelial cells. $J$ Toxicol Environ Health A. 2012;75(2):112-128.

36. Marchesan S, Kostarelos K, Bianco A, Prato M. The winding road for carbon nanotubes in nanomedicine. Mater Today. 2015;18(1): 12-19.

37. Weissker U, Hampel S, Leonhardt A, Büchner B. Carbon nanotubes filled with ferromagnetic materials. Materials. 2010;3(8): 4387-4427.

38. Authors not listed. The dose makes the poison. Nat Nanotechnol. 2011; 6:329.

39. Pampaloni F, Florin EL. Microtubule architecture: inspiration for novel carbon nanotube-based biomimetic materials. Trends Biotechnol. 2008; 26(6):302-310

40. Dinu CZ, Bale SS, Zhu G, Dordick JS. Tubulin encapsulation of carbon nanotubes into functional hybrid assemblies. Small. 2009;5(3): 310-315.

41. Jordan MA, Wilson L. Microtubules and actin filaments: dynamic targets for cancer chemotherapy. Curr Opin Cell Biol. 1998;10(1):123-130.

42. Zhang Y, Wang B, Meng X, Sun G, Gao C. Influences of acid-treated multiwalled carbon nanotubes on fibroblasts: proliferation, adhesion, migration, and wound healing. Ann Biomed Eng. 2011;39(1): 414-426.

43. Villegas JC, Álvarez-Montes L, Rodríguez-Fernández L, González J, Valiente R, Fanarraga ML. Multiwalled carbon nanotubes hinder microglia function interfering with cell migration and phagocytosis. Adv Healthc Mater. 2014;3(3):424-432.

44. García-Hevia L, Villegas JC, Fernández F, et al. Multiwalled carbon nanotubes inhibit tumor progression in a mouse model. Adv Healthc Mater. 2016;5(9):1080-1087.

45. Shelanski ML, Gaskin F, Cantor CR. Microtubule assembly in the absence of added nucleotides. Proc Natl Acad Sci U S A. 1973;70(3): 765-768.

46. Correa-Duarte MA, Kosiorek A, Kandulski W, Giersig M, LizMarzán LM. Layer-by-layer assembly of multiwall carbon nanotubes on spherical colloids. Chem Mater. 2005;17(12):3268-3272.

47. Correa-Duarte MA, Kosiorek A, Kandulski W, Giersig M, SalgueiriñoMaceira V. Nanoengineered polymeric thin films by sintering CNTcoated polystyrene spheres. Small. 2006;2(2):220-224.

48. Sanles-Sobrido M, Salgueiriño-Maceira V, Correa-Duarte MA, Liz-Marzán LM. Magnificent sea-anemone-like magnetic silica capsules reinforced with carbon nanotubes. Small. 2008;4(5): 583-586. 
49. Haniu H, Saito N, Matsuda Y, et al. Culture medium type affects endocytosis of multi-walled carbon nanotubes in BEAS-2B cells and subsequent biological response. Toxicol In Vitro. 2013;27(6): 1679-1685.

50. Yaron PN, Holt BD, Short PA, Lösche M, Islam MF, Dahl KN. Single wall carbon nanotubes enter cells by endocytosis and not membrane penetration. J Nanobiotechnology. 2011;9:45.
51. Holt BD, Short PA, Rape AD, Wang YL, Islam MF, Dahl KN. Carbon nanotubes reorganize actin structures in cells and ex vivo. ACS Nano. 2010;4(8):4872-4878.

52. García-Hevia L, Valiente R, González J, Fernández-Luna JL, Villegas JC, Fanarraga ML. Anti-cancer cytotoxic effects of multiwalled carbon nanotubes. Curr Pharm Des. 2015;21(15):1920-1929. 


\section{Supplementary material}
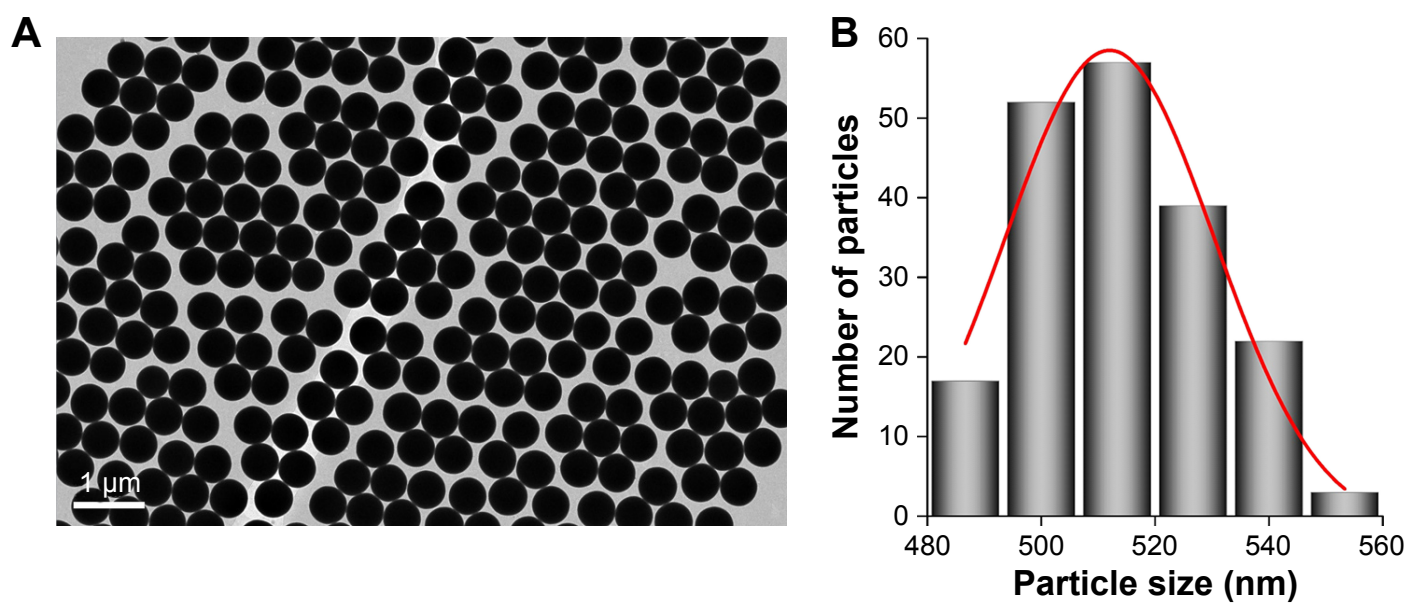

Figure SI (A) Transmission electron microscopy image of the synthesized silica nanoparticles, and (B) histogram of particle size distribution (mean size: 5 I $2 \pm 18$ nm).

\section{Publish your work in this journal}

The International Journal of Nanomedicine is an international, peerreviewed journal focusing on the application of nanotechnology in diagnostics, therapeutics, and drug delivery systems throughout the biomedical field. This journal is indexed on PubMed Central, MedLine, CAS, SciSearch ${ }^{\circledR}$, Current Contents ${ }^{\circledR} /$ Clinical Medicine,
Journal Citation Reports/Science Edition, EMBase, Scopus and the Elsevier Bibliographic databases. The manuscript management system is completely online and includes a very quick and fair peer-review system, which is all easy to use. Visit http://www.dovepress.com/ testimonials.php to read real quotes from published authors. 